\title{
Comparative Study of the Effect of Baicalin and Its Natural Analogs on Neurons with Oxygen and Glucose Deprivation Involving Innate Immune Reaction of TLR2/TNF $\alpha$
}

\author{
Hui-Ying Li, ${ }_{1}^{1}$ Jun Hu, ${ }^{1}$ Shuang Zhao, ${ }^{1}$ Zhi-Yi Yuan, ${ }^{1}$ Hong-Jiao Wan, ${ }^{2}$ Fan Lei, ${ }^{1}$ \\ Yi Ding, ${ }^{3}$ Dong-Ming Xing, ${ }^{1}$ and Li-Jun Du' ${ }^{1}$ \\ ${ }^{1}$ Protein Science Laboratory of the Ministry of Education, Laboratory of Pharmaceutical Sciences, \\ School of Life Sciences and School of Medicine, Tsinghua University, Beijing 100084, China \\ ${ }^{2}$ Jiangxi University of Traditional Chinese Medicine, Nanchang 330004, China \\ ${ }^{3}$ Drug Discovery Facility, School of Life Sciences, Tsinghua University, Beijing 100084, China
}

Correspondence should be addressed to Li-Jun Du, lijundu@mail.tsinghua.edu.cn

Received 28 July 2011; Revised 31 October 2011; Accepted 22 November 2011

Academic Editor: Ikhlas A. Khan

Copyright (C 2012 Hui-Ying Li et al. This is an open access article distributed under the Creative Commons Attribution License, which permits unrestricted use, distribution, and reproduction in any medium, provided the original work is properly cited.

\begin{abstract}
This work is to study the baicalin and its three analogs, baicalin, wogonoside, and wogonin, on the protective effect of neuron from oxygen-glucose deprivation (OGD) and toll-like receptor 2 (TLR2) expression in OGD damage. The results showed that baicalin and its three analogs did protect neurons from OGD damage and downregulated protein level of TLR2. D-Glucopyranosiduronic acid on site 7 in the structure played a core of cytotoxicity of these flavonoid analogs. The methoxyl group on carbon 8 of the structure had the relation with TLR2 protein expression, as well as the anti-inflammation. In addition, we detected caspase 3 and antioxidation capability, to investigate the effect of four analogs on cell apoptosis and total antioxidation competence in OGD model.
\end{abstract}

\section{Introduction}

Scutellariae radix, a Chinese medicine, has various pharmacological effects such as antibacterial, antivirus, antiinflammation, antioxidation, and antistroke in clinic [14]. Its active ingredient is a kind of flavones, consisting of baicalin, baicalein, wogonin, and wogoniside briefly (Figure 1) [5]. It is reported that Scutellariae radix protects neurons from the injury of ischemia and reperfusion [6]. Baicalin, the major component of the flavones, was confirmed with the neuroprotection of the damage by ischemia and reperfusion and the action on central nerve system [7-10]. Recently, baicalein was studied with a promising effect of neuroaction on multiple sites [11-17]. However, no report presented the effect of baicalin and TLR2 expression on neurons. A few researches reported that wogonin and wogonoside acted on the neurons [18-20]. Baicalin and baicalein were studied as an antioxidant; in a few models baicalein was even stronger than baicalin in reducing several free redials [21]. Comparing them, baicalein and baicalin significantly attenuated the cellular injury induced by hydrogen peroxide, but wogonin and wogonoside acted more weakly [22]. It is suggested that there must be other mechanisms of wogonin and wogonoside on neuroprotection.

As the anti-inflammation of baicalin and baicalein was confirmed, the researches on the innate immune response were studied in cerebral ischemia reperfusion and presented the reason partly why the anti-inflammation of baicalin and baicalein was one of the major assays for the protection of brain from the ischemia reperfusion damage [23-27]. Several receptors were indicated as the key targets of ischemic reperfusion injury in the glia, such as toll like receptors (TLRs) and the NODs (nucleotide-binding oligomerisation domain) [28-30]. Our prior experiment showed baicalin attenuated the expression of NOD2 and TNF $\alpha$ in neurons with the ischemia and reperfusion damage in vivo and 


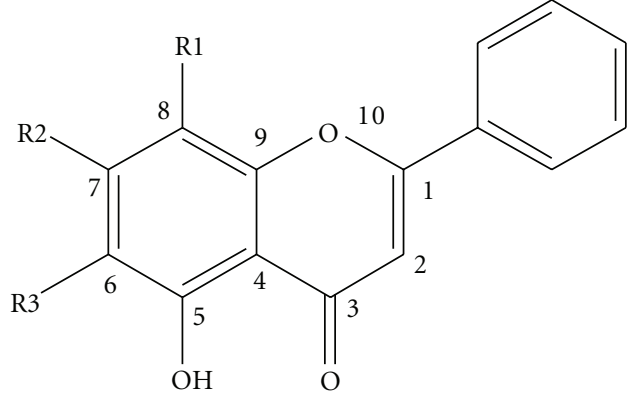

\begin{tabular}{llll}
\hline Compounds & $\mathrm{R} 1$ & $\mathrm{R} 2$ & $\mathrm{R} 3$ \\
\hline Baicalin & $-\mathrm{H}$ & $-\mathrm{O}-\mathrm{Glu}$ & $-\mathrm{OH}$ \\
Baicalein & $-\mathrm{H}$ & $-\mathrm{OH}$ & $-\mathrm{OH}$ \\
Wogonoside & $-\mathrm{OCH}_{3}$ & $-\mathrm{O}-\mathrm{Glu}$ & $-\mathrm{H}$ \\
Wogonin & $-\mathrm{OCH}_{3}$ & $-\mathrm{OH}$ & $-\mathrm{H}$ \\
\hline
\end{tabular}

FIgure 1: Chemical structures of baicalin and its natural analogs, baicalein, wogonoside, and wogonin.

in vitro [31]. Wogonoside was reported with inhibition of lipopolysaccharide-induced angiogenesis via toll-like receptor 4 (TLR4) signal transduction [32]. However, TLR2 has not been investigated by baicalin and its natural analogs.

Based on the previously mentioned information, we investigated the regulation behavior of baicalin and its analogs through one kind of neuron cell PC12 in order to explore the possible targets of baicalin and its analogs in innate immune reactions during the oxygen and glucose deprivation (OGD) and the relations between the chemical structure and the effect among baicalin and its natural analogs. Since TLR2 is one of the initial receptors in innate immunity and the inflammatory activation, as well as TNF $\alpha$, can be inhibited by baicalin in lung cells $[33,34]$, the protein expression of TLR2 and TNF $\alpha$ were tested to find out the role of baicalin and its analogs in this nerve injury models. Meanwhile, caspase3 is a well-known index of apoptosis, and several studies reported that a few flavones could induce apoptosis of inflammatory cells [35-37], so we detected the expression of caspase 3 protein. Additionally, the effect of the four analogs on the total antioxidation capability of cells in OGD model was also detected in this paper, which further compared the whole competence of these flavones [38].

\section{Materials and Methods}

2.1. Chemicals and Materials. Baicalin (purity was $98 \%$ ) was presented by Dr. Lujun Zhang, Laboratory of Pharmaceutical Sciences, Tsinghua University. Wogonoside (purity was 98\%) was presented by Dr. Xiuwei Yang, School of Pharmaceutical Science, Peking university. Baicalein and wogonin, all with purity of $98 \%$ (batch number 111595-200604 and 111514200403), were purchased from China National Institute for the Control of Pharmaceutical and Biological Products. Deionised water was used throughout the experiment. Other organic solvents and reagents were of analytical-reagent grade. PBS buffer with pH7.4 was prepared in our laboratory. PC12 cells were provided by the Cell Bank of the Institute of Fundamental Medicine, Chinese Academy of Medical Science (Beijing, China). Fetal bovine serum (FBS) and RPMI 1640 medium was purchased from GIBCO. AntiTLR2/TNF $\alpha /$ caspase3/ $\beta$-actin antibodies were purchased from Santa Cruz Company (USA). The secondary antibody was purchased from Zhongshan Company (Beijing, China). The Total antioxidation capability (T-AOC) detection kit was purchased from Nanjing Jiancheng Bioengineering Institute (Nanjing, China).

2.2. Cell Culture. PC12 cells were adjusted to about $1 \times$ $10^{6}$ cells $/ \mathrm{mL}$ with $2 \mathrm{~mL}$ inoculate into each well of 6 -well plates (Costar) in RPMI 1640 supplemented with 10\% fetal bovine serum (FBS) and 5\% horse serum and penicillin/streptomycin (100 U/mL each). Cells were cultured in a humidified incubator $\left(5 \% \mathrm{CO}_{2}\right)$ (Sanyo, Japan) at $37^{\circ} \mathrm{C}$ and allowed to attached for at least $48 \mathrm{~h}$.

2.3. Cytotoxicity Assays In Vitro. The safe dosages of baicalin and its three analogs to the cells were evaluated by MTT (methylthiazol tetrazolium) assay in vitro. After $24 \mathrm{~h}$ of cells incubation in 96-well plates, baicalin and its analogs were added with the dosage from $10 \mathrm{mg} / \mathrm{mL}$ to $0.001 \mathrm{mg} / \mathrm{mL}$. $24 \mathrm{~h}$ later of the compounds added, culture medium in 96well plates were incubated with MTT $(5 \mathrm{mg} / \mathrm{mL}, 200 \mu \mathrm{L}$ per well) at $37^{\circ} \mathrm{C}$ for $4 \mathrm{~h}$. Then the medium was carefully aspirated, and $200 \mu \mathrm{L}$ dimethylsulfoxide (DMSO) per well was added to dissolve the blue formazan products. The values of absorbance at $490 \mathrm{~nm}$ were measured using a microplate reader (Model 550Bio-RadUSA). The results of the absorbance of the test wells were expressed as cell alive. The $50 \%$ cytotoxicity concentration $\left(\mathrm{CC}_{50}\right)$ was calculated [39].

2.4. Cells for Oxygen-Glucose Deprivation. For the oxygenglucose deprivation (OGD) [40], we replaced the growth medium with glucose-free culture medium $(2 \mathrm{~mL}$ per well) and put the plates into an incubator (YCP-30Q, Changsha, China) full of $95 \% \mathrm{~N}_{2} / 5 \% \mathrm{CO}_{2}$ at $37^{\circ} \mathrm{C}$ for $120 \mathrm{~min}$. Then cells were returned to the normal feeding medium and incubated under normal conditions at $37^{\circ} \mathrm{C}$ (Sanyo, Japan) for the specific time for later experiments. Control cell cultures not deprived of oxygen and glucose were incubated under normal conditions in the medium with glucose.

For protective effect of the compounds from OGD damage, the cell living assay was carried out as previously described. After $24 \mathrm{~h}$ of cells incubation in 96-well plates, baicalin and its analogs were added with the dosages from $10 \mathrm{mg} / \mathrm{mL}$ to $0.001 \mathrm{mg} / \mathrm{mL}$. $24 \mathrm{~h}$ later from adding the compounds, culture medium in 96-well plates was incubated with MTT $\left(5 \mathrm{mg} / \mathrm{mL}, 200 \mu \mathrm{L}\right.$ per well) at $37^{\circ} \mathrm{C}$ for $4 \mathrm{~h}$. The medium was carefully aspirated, and $200 \mu \mathrm{L}$ DMSO per well was added to dissolve the blue formazan products. The values of absorbance at $490 \mathrm{~nm}$ were measured using a microplate reader. The results of the absorbance of the 
test wells were expressed as cell alive. The $50 \%$ effective concentration $\left(\mathrm{EC}_{50}\right)$ was calculated [39]. Combined with cytotoxicity $\left(\mathrm{CC}_{50}\right)$ of the compounds, the safety indices (SIs) were calculated by $\mathrm{EC}_{50} / \mathrm{CC}_{50}[41]$.

For TLR2/TNF $\alpha$ and caspase3 study, the minimum safety concentration of baicalin and its analogs was ordered as $10 \mu \mathrm{g} / \mathrm{mL}$. These compounds $(10 \mu \mathrm{g} / \mathrm{mL})$ were added when culture medium was exchanged with glucose solution and cells were cultured in normal condition. The cells were picked up for protein experiment at the specific reperfusion time $(0.5,1,3,6 \mathrm{~h})$ after baicalin and its analogs added. In control, medium was used as a vehicle and the cells were picked up at the reperfusion time of $6 \mathrm{~h}$.

2.5. Preparation of Samples. Two groups without medicines were employed as control. One group of the cells was seeded in the medium with normal growth medium during all the experimental process without oxygen-glucose deprivation. The second group was seeded in the medium with process of oxygen-glucose deprivation as the model control. At each time point, the cell sample was prepared the same as previous description. The medium was drawn out from each well, and cells were washed three times with cold PBS ( $\mathrm{pH}$ 7.4) and used with $100 \mu \mathrm{L}$ RIPA to gather total protein for Western blotting.

2.6. Western Blot. Western blot assay for protein expression of $\beta$-actin, TLR2, TNF $\alpha$, and Caspase 3 was referenced in [42] with minimodification as follows: loaded samples into the gel $(10 \%)$, was run until the marker (purchased from Fermentas Republic of Lithuania) and went to the end of the gel. The transfer should be semidry for $60 \mathrm{~min}$ at 12 volts and $280 \mathrm{~mA}$. Then the membrane was blocked with $10 \%$ milk in PBST $(1 \times$ PBS $+0.1 \%$ Tween 20$)$ for 60 min shaking slowly at room temperature. The membrane was put in $1 \mathrm{~mL}$ PBST with antibody in a $1: 1000$ dilution, incubated for $60 \mathrm{~min}$ at room temperature on the shaker, and washed for 3 times using PBST after the primary antibody incubation. After that, the membrane was incubated for $60 \mathrm{~min}$ in PBST with the secondary antibody with the concentration $1: 3000$. The membrane was washed 3 times with PBST at last.

2.7. Total Antioxidation Capability Detection. The principle of this experiment was to detect the color change following the reduction of $\mathrm{Fe}^{3+}$ to $\mathrm{Fe}^{2+}$ by the reducing components in the samples. The reducing components might include the enzyme and nonenzymatic molecules such as lipidsoluble antioxidant vitamin $\mathrm{E}$ and water-soluble antioxidants vitamin C, bilirubin, and uric acid. Then the optical density was measured at $520 \mathrm{~nm}$ with a microplate reader [43]. The cell sample was prepared the same as previous description and picked at the specific reperfusion time (6h) after baicalin and its analogs added. The medium was drawn out from each well, and the cells were washed three times with cold PBS ( $\mathrm{pH}$ 7.4). These cells in the plate were resolved with PBS $(1 \mathrm{~mL} /$ well $)$ by repeated freezing and thawing. The supernatant was collected for T-AOC test after centrifuge $12000 \mathrm{rpm} / \mathrm{min}$.
2.8. Data Analysis. All values were expressed as mean \pm S.D. Data were statistically analyzed by ANOVA. The NewmanKeuls comparisons were used to determine the source of significant differences where appropriate. $P$ values below 0.05 were considered statistically significant. The software of CALC 2.0 (The China Association of Pharmacology) was employed for $\mathrm{CC}_{50}$ and $\mathrm{EC}_{50}$ calculation.

\section{Results}

3.1. Cell Growing Profile. The cells were seeded in the plates of the medium with $10 \%$ FBS for $48 \mathrm{~h}$. They would not be used for the experiments till they grew well and attached to each other tightly in the flat of multiwell plates.

3.2. MTT Tests of Cytotoxicity. In order to examine the cytotoxicity and determine the safe dosages of baicalin and its analogs, MTT assay was conducted on PC12 cells in vitro. Based on the experiments, $10 \mu \mathrm{g} / \mathrm{mL}$ of baicalin and wogonoside was the highest in safety concentration on normal PC12 cells, and $1 \mu \mathrm{g} / \mathrm{mL}$ of baicalein and wogonin was the highest in safety concentration on normal PC12 cells (Figure 2).

In PC12 cells treated with oxygen-glucose deprivation, only less than $40 \%$ cells survived with comparison of normal control $(P<0.05)$. Compared with model control, the minimum effective concentration (MEC) of baicalin and wogonin was $10 \mu \mathrm{g} / \mathrm{mL}$, while the MEC of both wogonoside and baicalein was the same at $1 \mu \mathrm{g} / \mathrm{mL}$. The maximum effective concentration (MAXEC) of baicalin and woronin was the same at $1 \mathrm{mg} / \mathrm{mL}$, implying the same safety of them. The MAXEC of wogonoside was $1 \mathrm{mg} / \mathrm{mL}$, but the MAXEC of baicalein was only at $10 \mu \mathrm{g} / \mathrm{mL}$. It was suggested that baicalein was more cytotoxic than that of wogonoside. All these compounds were not shown in the concentrationdependent manner distinctly (Figure 3 ).

The $\mathrm{CC}_{50}$ of baicalin $(188.4 \mu \mathrm{g} / \mathrm{mL}$ or $0.422 \mathrm{mmol} / \mathrm{L})$ showed large differences from other three compounds. Baicalein showed more cellular toxicity with $\mathrm{CC}_{50} 8.9 \mu \mathrm{g} / \mathrm{mL}$ (equal to $0.0329 \mathrm{mmol} / \mathrm{L}$ ). Wogonin and wogonoside displayed toxicity similar to $\mathrm{CC}_{50} 10.6 \mu \mathrm{g} / \mathrm{mL}$ (equal to $0.0373 \mathrm{mmol} / \mathrm{L}$ ) and $13.7 \mu \mathrm{g} / \mathrm{mL}$ (equal to $0.0298 \mathrm{mmol} / \mathrm{L}$ ), respectively. However, baicalein was more effective of protection of the cells from OGD damage. The minimum effective dosage of baicalein was $1 \mu \mathrm{g} / \mathrm{mL}$ (equal to $0.0037 \mathrm{mmol} / \mathrm{L}$ ). The $\mathrm{EC}_{50}$ of baicalin was $1.2 \mu \mathrm{g} / \mathrm{mL}$ (equal to $0.0027 \mathrm{mmol} / \mathrm{L}$ ), and the $\mathrm{EC}_{50}$ of Wogonin and wogonoside was $4.3 \mu \mathrm{g} / \mathrm{mL}$ (equal to $0.0151 \mathrm{mmol} / \mathrm{L}$ ) and $7.4 \mu \mathrm{g} / \mathrm{mL}$ (equal to $0.0161 \mathrm{mmol} / \mathrm{L}$ ). Comparing between the toxicity and the effect, the safety indices of the four compounds were 156 (baicalin), 8.89 (baicalein), 2.47 (wogonin), and 1.85 (wogonoside), respectively (Table 1).

3.3. Effect on the Expressions of TLR2, TNF $\alpha$, and Caspase3. Injured by OGD, the proteins of TLR2 and TNF $\alpha$ in the cells were expressed distinctly which means the OGD stimulated the innate immune reaction, causing inflammation. The caspase 3 protein in OGD model was upregulated in 

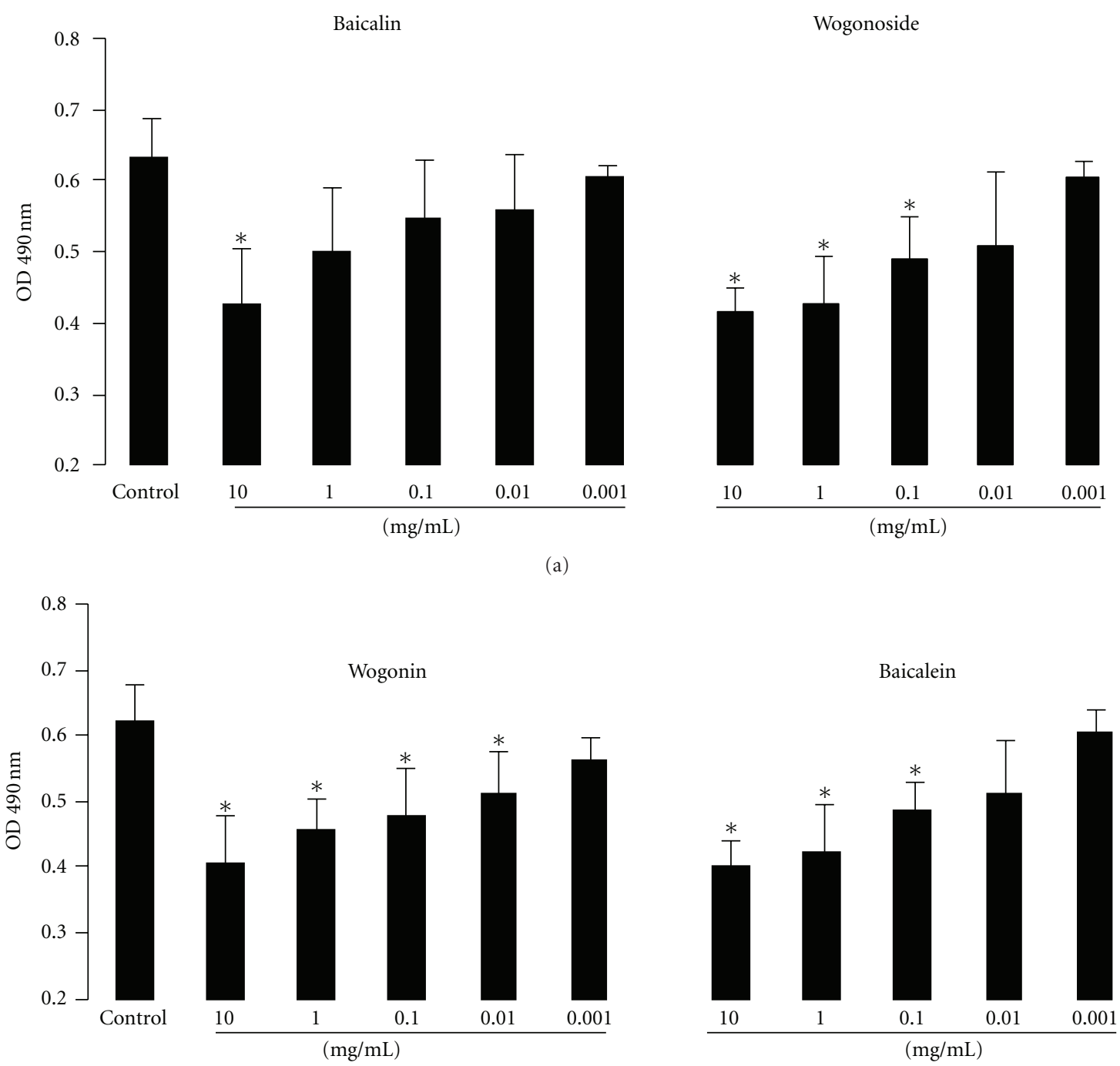

(b)

FIgure 2: Cytotoxcity of baicalin, wogonoside, baicalein, and wogonin in normal PC12 cells (MTT assay). After $24 \mathrm{~h}$ of cells incubation in 96 -well plates, the chemicals were added with the dosage from $10 \mathrm{mg} / \mathrm{mL}$ to $0.001 \mathrm{mg} / \mathrm{mL} .{ }^{*} P<0.05$ versus normal control. Data were presented as mean \pm S.D. from seven independent experiments.

TABLE 1: Values of $\mathrm{CC}_{50}$ and $\mathrm{EC}_{50}$ of baicalin, baicalein, wogonoside, and wogonin.

\begin{tabular}{lccc}
\hline Compounds & $\begin{array}{c}\mathrm{CC}_{50} \\
\mu \mathrm{g} / \mathrm{mL}(\mathrm{mmol} / \mathrm{L})\end{array}$ & $\begin{array}{c}\mathrm{EC}_{50} \\
\mu \mathrm{g} / \mathrm{mL}(\mathrm{mmol} / \mathrm{L})\end{array}$ & $\mathrm{SI}$ \\
\hline Baicalin & $188.4(0.422)$ & $1.2(0.0027)$ & 156 \\
Wogonoside & $13.7(0.0298)$ & $7.4(0.0161)$ & 1.85 \\
Baicalein & $8.9(0.0329)$ & $1.0(0.0037)$ & 8.89 \\
Wogonin & $10.6(0.0373)$ & $4.3(0.0151)$ & 2.47 \\
\hline
\end{tabular}

$\mathrm{CC}_{50}$ means the $50 \%$ cytotoxic concentration.

$\mathrm{EC}_{50}$ means the $50 \%$ effective concentration.

SI (the safety index) was calculated by $\mathrm{CC}_{50} / \mathrm{EC}_{50}$.

some degree, but there was no significant statistical value (Figure 4). Baicalin attenuated the protein expression of TLR2 and TNF $\alpha 3$ hours after the administration. When baicalin took effect for $0.5 \mathrm{~h}$, the expression of TLR2 showed statistical significance no matter when compared with the normal or comparing with the model $(P<0.05)$, and the TLR2 expression of $1 \mathrm{~h}$ increased (comparing with the normal, $P<0.05$ ); however, its expression of $3 \mathrm{~h}$ or $6 \mathrm{~h}$ showed no obvious difference comparing with the normal (comparing with the model, $P<0.05$ ). The expression of TNF $\alpha$ of $0.5 \mathrm{~h}$ was still higher than the control $(P<0.05)$, and its expressions of $1 \mathrm{~h}, 3 \mathrm{~h}$, and $6 \mathrm{~h}$ were downregulated obviously, which showed significant difference from the model level $(P<0.05)$. Baicalin did not apparently affect the expression of protein caspase3, which was shown in Figure 4(a).

After the addition of wogonoside $(10 \mu \mathrm{g} / \mathrm{mL})$, TLR2 and TNF $\alpha$ were downregulated apparently. The expression of TLR2 was much lower than that of the model, even than the normal level $(P<0.05)$. Accordingly, the expression of 


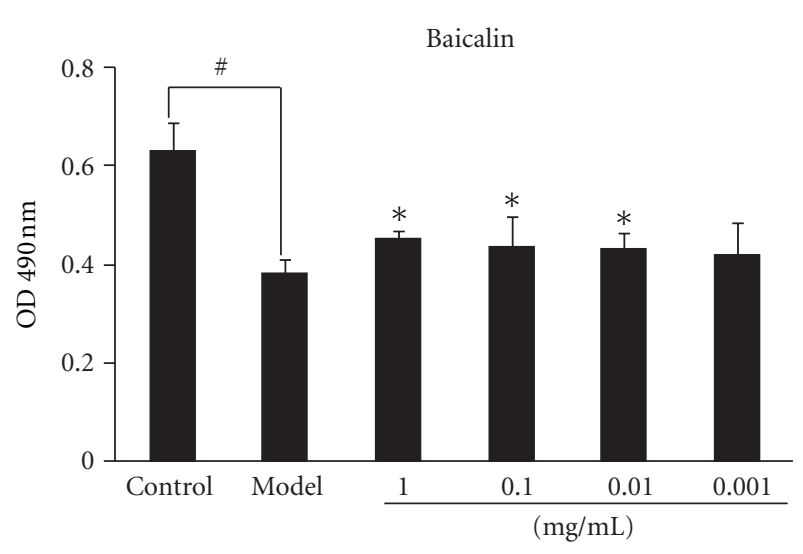

(a)

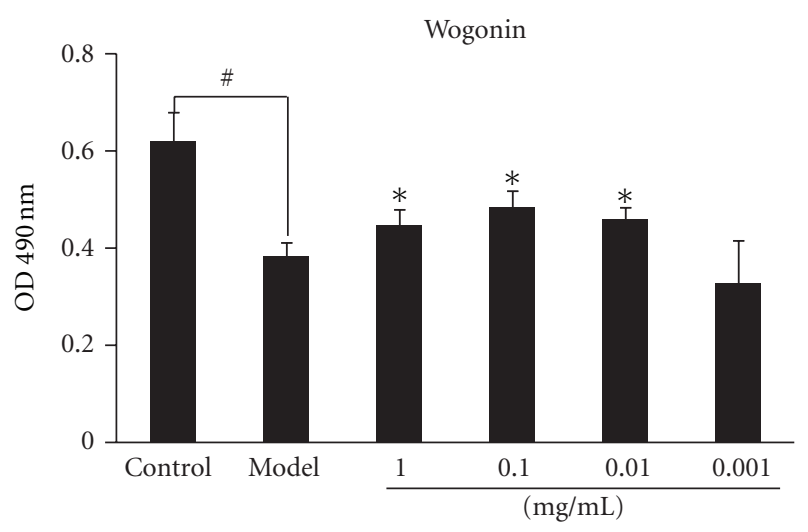

(c)

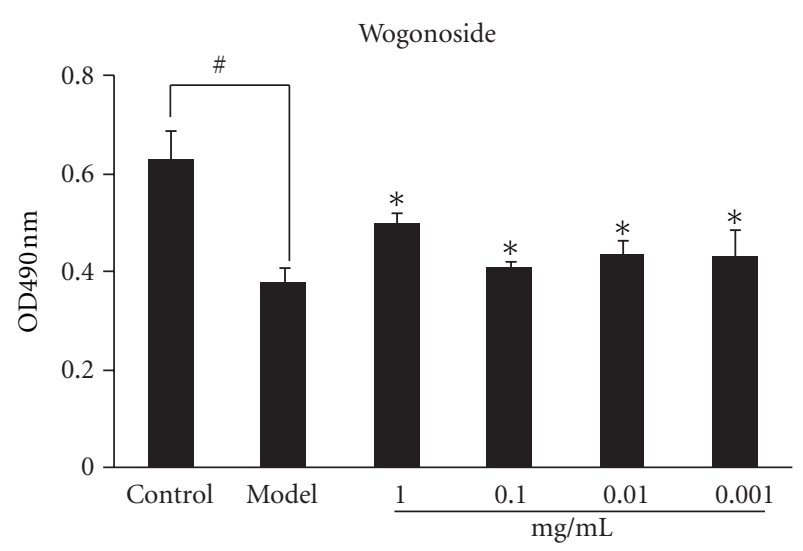

(b)

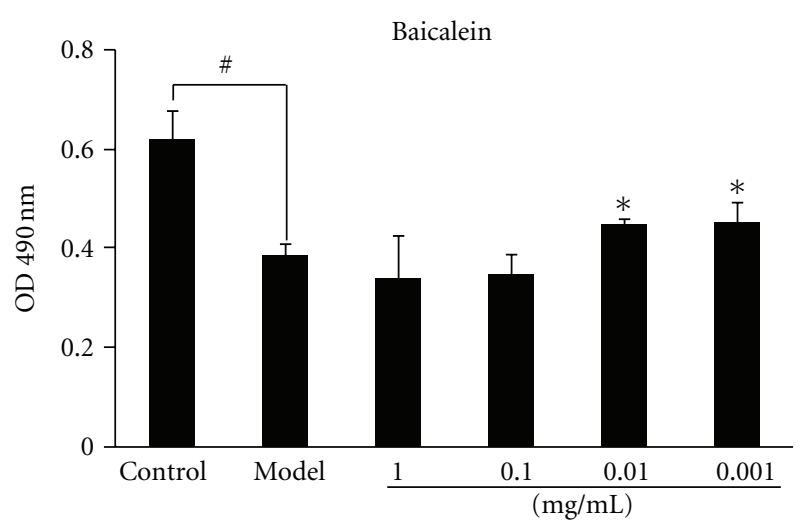

(d)

FIgURE 3: Protection of baicalin, wogonoside, baicalein, and wogonin in PC12 cell with oxygen-glucose deprivation (OGD) (MTT assay). After $24 \mathrm{~h}$ of cells incubation in 96-well plates and $2 \mathrm{~h}$ oxygen-glucose deprivation, the compounds were added with the dosage from $1 \mathrm{mg} / \mathrm{mL}$ to $0.001 \mathrm{mg} / \mathrm{mL}$. ${ }^{\#} P<0.05$ versus normal control. ${ }^{*} P<0.05$ versus model. Data were presented as mean \pm S.D. from seven independent experiments.

TNF $\alpha$ was inhibited by wogonoside apparently from $0.5 \mathrm{~h}$ after its administration till the timepoint of $6 \mathrm{~h}(P<$ 0.05). Wogonoside also did not show obvious effect on the expression of caspase3 (Figure 4(b)).

After baicalein administration, TLR2 was still upregulated significantly $0.5 \mathrm{~h}$ and $1 \mathrm{~h}$ after the addition of baicalein $(P<0.05)$, and it decreased down to the normal at $3 \mathrm{~h}$ and $6 \mathrm{~h}$. Comparing with the model, TNF $\alpha$ was upregulated at $0.5 \mathrm{~h}$ and decreased gradually later. Like TLR2, it was expressed down to the normal at $3 \mathrm{~h}$ and $6 \mathrm{~h}$ (Figure $4(\mathrm{c})$ ).

In wogonin group, the two factors decreased apparently. TLR2 decreased to the normal after $0.5 \mathrm{~h}$ of the addition of wogonin (comparing with the model, $P<0.05$ ), and it stayed at a lower level during the experiment course. In the $0.5 \mathrm{~h}$ and $1 \mathrm{~h}$ time points, TNF $\alpha$ was expressed more than the normal $(P<0.05)$ but less than the model $(P<0.05)$, and at $3 \mathrm{~h}$ and $6 \mathrm{~h}$, it came close to the normal level like TLR2 expression (Figure 4(d)).

Similar to baicalin and wogonoside groups, the expression of caspase 3 showed no significant change in baicalein and wogonin groups (Figures 4(c) and 4(d)).

3.4. Assay of Total Antioxidation Competence (T-AOC). Utilizing the T-AOC kit, we found that the antioxidation competence of the normal cells was about $2.5 \mathrm{U} / \mathrm{mg}$, and one of the cells treated by oxygen-glucose deprivation was far below $0.5 \mathrm{U} / \mathrm{mg}$. In baicalin group, the detection value was $1.8 \mathrm{U} / \mathrm{mL}$, showing a significant difference no matter comparing with the normal or comparing with the OGD model. In wogonoside, baicalein, and wogonin groups, the values were $1.6,0.8$, and $0.6 \mathrm{U} / \mathrm{mg}$, respectively, which all showed a significant difference comparing with the normal or the model (Figure 5).

\section{Discussions}

Baicalin is a glycosylated compound derived from baicalein, and it has a functional group of D-glucopyranosiduronic acid on site 7 of baicalein (Figure 1), so that it will exhibit more biological function. The basic structure of baicalin consists of benzopyran with three hydroxyl groups at site 5,6 , and 7 and a phenyl group at the other side of the benzopyran (site 2). Baicalin also has an enol structure on the benzopyran ring to maintain the conjugation. The two differences between baicalin and wogonin lie in methoxyl group on carbon 8 of wogonin and hydroxyl group on carbon 6 of baicalein. The constitution of three hydroxyl groups in baicalin may account for more hydrophilic characters. 


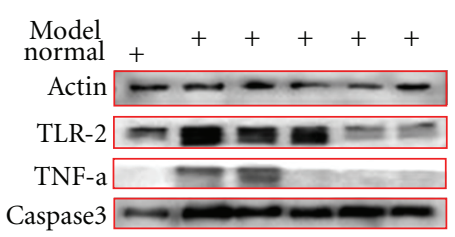

\begin{tabular}{llll}
0.5 & 1 & 3 & $6(\mathrm{~h})$ \\
\hline
\end{tabular}

Baicalin $(10 \mu \mathrm{g} / \mathrm{mL})$
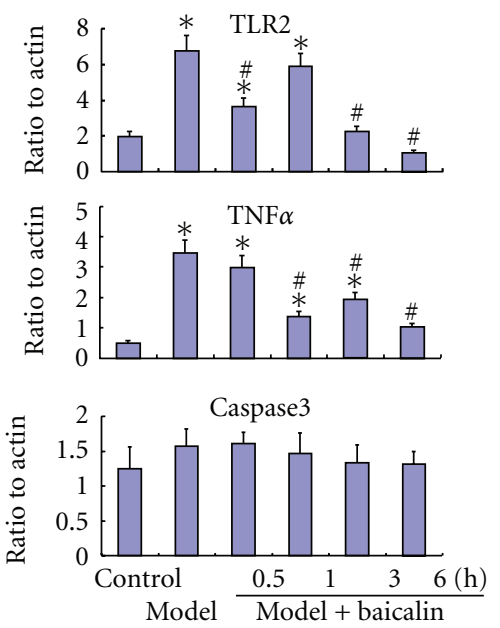

(a)
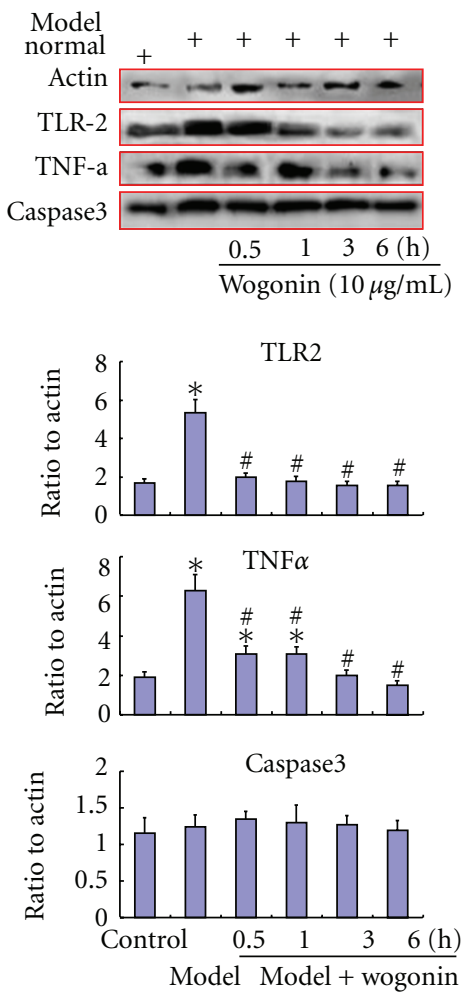

(c)
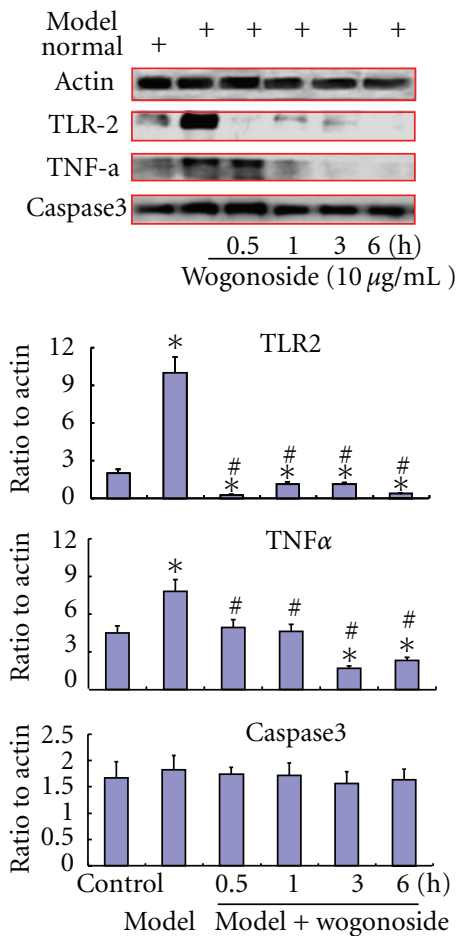

(b)
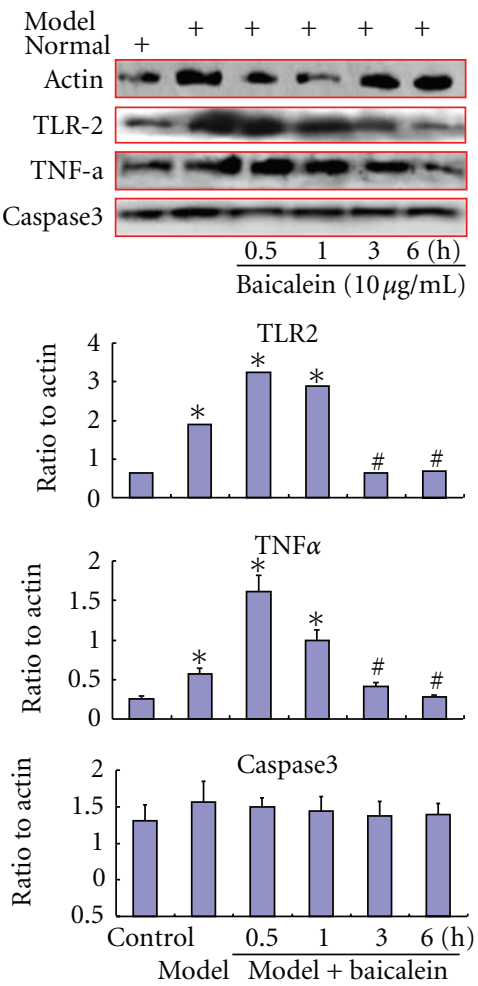

(d)

FIGURE 4: Effect of the four analogs on the protein expressions of TLR2, TNF $\alpha$, and caspase 3 in PC12 cells with oxygen-glucose deprivation (OGD). The protein level was measured by Western blot. Model means treatment with oxygen-glucose deprivation. 0.5, 1, 3, and 6 h mean the time of reperfusion process after OGD. (a) stands for baicalin effect; (b) stands for wogonoside effect; (c) stands for baicalein effect; (d) stands for wogonin effect. Baicalin, wogonoside, and wogonin were used in a concentrating of $10 \mu \mathrm{g} / \mathrm{mL}$, and the baicalein was used in a concentrating of $1 \mu \mathrm{g} / \mathrm{mL} .{ }^{*} P<0.05$ versus normal control. ${ }^{*} P<0.05$ versus model group. Data were presented as mean $\pm \mathrm{SD}$ from three independent experiments. 


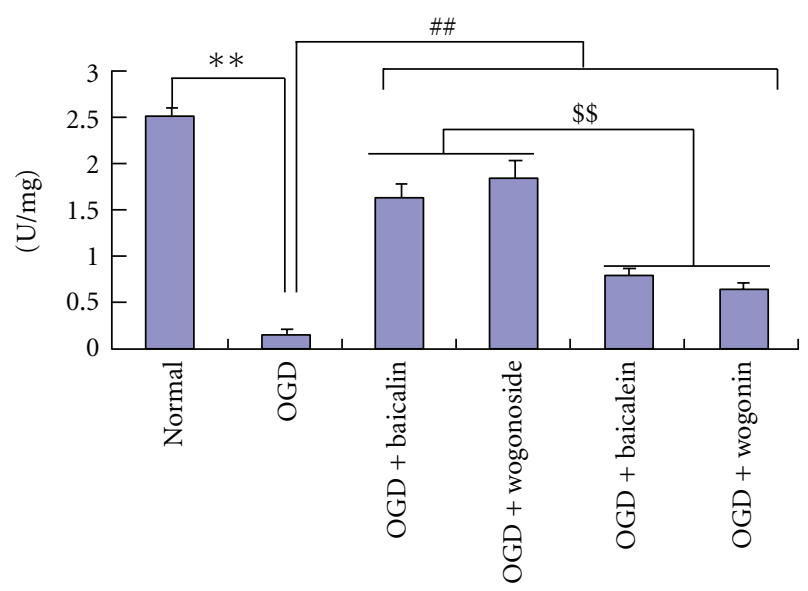

Figure 5: Effect of baicalin and its three analogs on the total antioxidation competence of the PC12 cells treated with oxygenglucose deprivation. Model means treatment with oxygen-glucose deprivation. Baicalin, wogonoside, and wogonin were used in a concentrating of $10 \mu \mathrm{g} / \mathrm{mL}$, the baicalein was used in a concentrating of $1 \mu \mathrm{g} / \mathrm{mL}$. ${ }^{* *} P<0.01$ versus normal control. ${ }^{\#} P<0.01$ versus model group. ${ }^{\$} P<0.01$ versus baicalin and wogonoside groups. Data were presented as mean \pm S.D. from eight independent experiments.

Moreover, wogonoside is a glycosylated form of wogonin with D-glucopyranosiduronic acid on carbon 7. All four compounds share similar carbon skeleton with a benzopyran structure and also a hydroxyl group on carbon 5; baicalein and baicalin have hydroxyl groups on carbon 6 , while wogonin and wogonoside does not have; baicalein and wogonin have hydroxyl groups on carbon 7, while wogonoside and baicalin are both glycosylated on the hydroxyl group at site 7; last, wogonin and wogonoside have methoxyl groups on carbon 8 , but baicalein and baicalin does not have the functional groups $[44,45]$.

By the result of cytotoxicity and neuroprotection, Dglucopyranosiduronic acid on site 7 was important for reducing cytotoxicity, in which baicalin was less cytotoxic than baicalein and wogonoside was less cytotoxic than wogonin. Methoxyl group on carbon 8 and hydroxyl group on carbon 6 were the major factor influencing the neuroprotective effect, by which the $\mathrm{EC}_{50}$ of baicalin and baicalein was less than that of wogonoside and wogonin (Figure 1 and Table 1) after they were administered.

In this study, we found that TLR2 was highly expressed during the oxygen and glucose deprivation (OGD) damage in PC12 cells, which suggested that the receptor was activated in the damaged neurons (Figure 4). TLR2 had been identified as a key mediator of immune responses and inflammatory reactions, and it mediated proinflammatory responses through activating of TNF $\alpha$ [46-48]. The receptor was significantly up-regulated comparing with the normal level, indicating it joined neuron injury induced by OGD.

By the literature of research, TLR2 in the central nerve system (CNS) is realized as the direct source of the damaging signal and an important potential therapeutic target [49]. In our results, the expressions of TLR2 and TNF $\alpha$ decreased apparently a few hours after we added the compounds.
In the same profile, the expressions of TLR2 and TNF $\alpha$ with wogonin and wogonoside were more inhibited than those with baicalin and baicalein. The inhibition of the expression started from $0.5 \mathrm{~h}$ after wogonin and wogonoside administration; however the inhibition of TLR2 and TNF $\alpha$ expression appeared later at $3 \mathrm{~h}$ after baicalin and baicalein administration. Therefore, wogonin and wogonoside were realized to have preference with TLR2. Combined with their chemical structures, all the results implied that methoxyl group on carbon 8 in the structure is the pharmacophore hypothesis of the effect of TLR2 inhibition, relating to inflammation inhibition.

Conditioning the oversuppression on TLR2 and TNF $\alpha$ by these analogs, we detected caspase 3 to confirm whether there existed apoptosis with the addition of the analogs. Comparing with the normal, the expression of caspase3 protein in OGD model indeed increased in some degree, but showed no statistical difference. With the administration of the four analogs, the level caspase 3 protein showed no obvious change, although it showed the tendency to decrease at $6 \mathrm{~h}$ time point and near to the normal control (comparing with the normal or the model, $P>0.05$ ). The above results suggested the injured PC12 cells in OGD model had no apparent apoptosis, and the four analogs also could not induce apoptosis in the injured PC12 cells. According to the literature, baicalin attenuated global cerebral ischemia reperfusion injury in gerbils via antioxidative and antiapoptotic pathways [50], and baicalein and wogonin could both induce the apoptosis in human pancreatic cancer cells and HL-60 leukemia cells $[51,52]$. Therefore, our results of apoptosis by these compounds need to be studied further.

Referring to the T-AOC detection, we found that the total antioxidation capability sequence was baicalin and wogonoside > baicalein and wogonin, indicating that a glycosylated form on site 2 of baicalin and wogonoside played a key role in overall antioxidation.

Taken together, baicalin and its three analogs presented comprehensively the protection of neuron cells from OGD damage and the inhibition of TLR2 expression and TNF $\alpha$ (the factor in the downstream), suggesting the possibility of these compounds used in stroke therapy by targeting TLR2, one of the major mechanisms of the cerebral damage. There is a structure-activity relationship among them with safety, efficacy, and specificity of drug targeting of TLR2. This is the first time to study baicalin and its natural analogs on molecular targets of TLR 2 and TNF $\alpha$, as well as T-AOC. All that will have benefit in elucidating and developing them for the new drugs.

\section{Authors' Contribution}

The first two authors contributed equally.

\section{Acknowledgments}

The author thank all members in their laboratory. The study was supported partly by the National Natural Science Foundation of China (30801523, 81073092), the National S\&T Major Special Project for New Drug R\&D 
of China (2012ZX09103-201-041, 2012ZX09102-201-008, and 2011ZX09101-002-11), and Special Foundation for Laboratory of Tsinghua University (LF 20103579).

\section{References}

[1] L. L. Liu, L. K. Gong, H. Wang et al., "Baicalin inhibits macrophage activation by lipopolysaccharide and protects mice from endotoxin shock," Biochemical Pharmacology, vol. 75, no. 4, pp. 914-922, 2008.

[2] S. H. Jung, K. D. Kang, D. Ji et al., "The flavonoid baicalin counteracts ischemic and oxidative insults to retinal cells and lipid peroxidation to brain membranes," Neurochemistry International, vol. 53, no. 6-8, pp. 325-337, 2008.

[3] K. J. Woo, J. H. Lim, S. I. Suh et al., "Differential inhibitory effects of baicalein and baicalin on LPS-induced cyclooxygenase- 2 expression through inhibition of $\mathrm{C} / \mathrm{EBP} \beta$ DNA-binding activity," Immunobiology, vol. 211, no. 5, pp. 359-368, 2006.

[4] Y. C. Chen, J. M. Chow, C. W. Lin, C. Y. Wu, and S. C. Shen, "Baicalein inhibition of oxidative-stress-induced apoptosis via modulation of ERKs activation and induction of HO-1 gene expression in rat glioma cells C6," Toxicology and Applied Pharmacology, vol. 216, no. 2, pp. 263-273, 2006.

[5] J. Zhu, Z. Wang, Q. Zhang, J. Niu, and F. Li, "A quantitative method for simultaneous assay of four flavones with one marker in Radix Scutellariae," China Journal of Materia Medica, vol. 34, no. 24, pp. 3229-3234, 2009.

[6] W. J. Xu and Q. L. Ding, "Pharmacological research of baicalin," Jiangsu Pharmaceutical and Clinical Research, vol. 14, no. 2, pp. 103-107, 2006.

[7] T. Tarragó, N. Kichik, B. Claasen, R. Prades, M. Teixidó, and E. Giralt, "Baicalin, a prodrug able to reach the CNS, is a prolyl oligopeptidase inhibitor," Bioorganic and Medicinal Chemistry, vol. 16, no. 15, pp. 7516-7524, 2008.

[8] X. Wang, L. Zhang, L. Hua, D. Xing, and L. Du, "Effect of flavonoids in Scutellariae Radix on depression-like behavior and brain rewards: possible in dopamine system," Tsinghua Science and Technology, vol. 15, no. 4, pp. 460-466, 2010.

[9] L. Chen, L. Zhang, X. Wang, H. Lin, and L. Du, "Determination of dopamine and its relativity of baicalin in rat nuclei after intravenous administration of flavonoids from Scutellariae radix," Biomedical Chromatography, vol. 21, no. 1, pp. 84-88, 2007.

[10] C. H. Ouyang and J. L. Wu, "Protective effect of baicalin on inflammatory injury following transient focal cerebral ischemia-reperfusion in rats," Chinese Journal of Pharmacology and Toxicology, vol. 20, no. 4, pp. 288-294, 2006.

[11] S. J. Park, D. H. Kim, J. M. Kim et al., "Mismatch between changes in baicalein-induced memory-related biochemical parameters and behavioral consequences in mouse," Brain Research, vol. 1355, pp. 141-150, 2010.

[12] X. Mu, G. He, Y. Cheng, X. Li, B. Xu, and G. Du, "Baicalein exerts neuroprotective effects in 6-hydroxydopamine-induced experimental parkinsonism in vivo and in vitro," Pharmacology Biochemistry and Behavior, vol. 92, no. 4, pp. 642-648, 2009.

[13] P. H. Wu, Y. C. Shen, Y. H. Wang, C. W. Chi, and J. C. Yen, "Baicalein attenuates methamphetamine-induced loss of dopamine transporter in mouse striatum," Toxicology, vol. 226, no. 2-3, pp. 238-245, 2006.

[14] X. L. He, Y. H. Wang, M. Gao, X. X. Li, T. T. Zhang, and G. H. Du, "Baicalein protects rat brain mitochondria against chronic cerebral hypoperfusion-induced oxidative damage," Brain Research, vol. 1249, pp. 212-221, 2009.

[15] L. Cui, X. Zhang, R. Yang et al., "Baicalein is neuroprotective in rat MCAO model: role of 12/15-lipoxygenase, mitogenactivated protein kinase and cytosolic phospholipase A2," Pharmacology Biochemistry and Behavior, vol. 96, no. 4, pp. 469-475, 2010.

[16] C. Liu, J. Wu, J. Gu et al., "Baicalein improves cognitive deficits induced by chronic cerebral hypoperfusion in rats," Pharmacology Biochemistry and Behavior, vol. 86, no. 3, pp. 423-430, 2007.

[17] Y. W. Xu, L. Sun, H. Liang, G. M. Sun, and Y. Cheng, "12/15-Lipoxygenase inhibitor baicalein suppresses PPAR $\gamma$ expression and nuclear translocation induced by cerebral ischemia/reperfusion," Brain Research, vol. 1307, pp. 149-157, 2010.

[18] H. Z. Piao, I. Y. Choi, J. S. Park et al., "Wogonin inhibits microglial cell migration via suppression of nuclear factorkappa B activity," International Immunopharmacology, vol. 8, no. 12, pp. 1658-1662, 2008.

[19] H. G. Park, S. Y. Yoon, J. Y. Choi et al., "Anticonvulsant effect of wogonin isolated from Scutellaria baicalensis," European Journal of Pharmacology, vol. 574, no. 2-3, pp. 112-119, 2007.

[20] W. Tang, X. Sun, J. S. Fang, M. Zhang, and N. J. Sucher, "Flavonoids from Radix Scutellariae as potential stroke therapeutic agents by targeting the second postsynaptic density 95 (PSD-95)/disc large/zonula occludens-1 (PDZ) domain of PSD-95," Phytomedicine, vol. 11, no. 4, pp. 277-284, 2004.

[21] R. Liang, C. H. Chen, X. C. Ai, and J. P. Zhang, "Structural origins of the differential antioxidative activities between baicalein and baicalin," Chinese Journal of Magnetic Resonance, vol. 27, pp. 132-140, 2010.

[22] Z. Gao, K. Huang, and H. Xu, "Protective effects of flavonoids in the roots of Scutellaria Baicalensis Georgi against hydrogen peroxide-induced oxidative stress in HS-SY5Y cells," Pharmacological Research, vol. 43, no. 2, pp. 173-178, 2001.

[23] M. Letiembre, W. Hao, Y. Liu et al., "Innate immune receptor expression in normal brain aging," Neuroscience, vol. 146, no. 1, pp. 248-254, 2007.

[24] B. J. Marsh, R. L. Williams-Karnesky, and M. P. Stenzel-Poore, "Toll-like receptor signaling in endogenous neuroprotection and stroke," Neuroscience, vol. 158, no. 3, pp. 1007-1020, 2009.

[25] G. J. del Zoppo, "Inflammation and the neurovascular unit in the setting of focal cerebral ischemia," Neuroscience, vol. 158, no. 3, pp. 972-982, 2009.

[26] B. W. McColl, S. M. Allan, and N. J. Rothwell, "Systemic infection, inflammation and acute ischemic stroke," Neuroscience, vol. 158, no. 3, pp. 1049-1061, 2009.

[27] D. A. Ridder and M. Schwaninger, "NF- $\kappa$ B signaling in cerebral ischemia," Neuroscience, vol. 158, no. 3, pp. 995-1006, 2009.

[28] P. Rosenstiel, G. Jacobs, A. Till, and S. Schreiber, "NOD-like receptors: ancient sentinels of the innate immune system," Cellular and Molecular Life Sciences, vol. 65, no. 9, pp. 13611377, 2008.

[29] V. S. Chauhan, D. G. Sterka, S. R. Furr, A. B. Young, and I. Marriott, "NOD2 plays an important role in the inflammatory responses of microglia and astrocytes to bacterial CNS pathogens," GLIA, vol. 57, no. 4, pp. 414-423, 2009.

[30] K. Geddes, J. G. Magalhães, and S. E. Girardin, "Unleashing the therapeutic potential of NOD-like receptors," Nature Reviews Drug Discovery, vol. 8, no. 6, pp. 465-479, 2009.

[31] H. Li, J. Hu, L. Ma et al., "Comprehensive study of baicalin down-regulating NOD2 receptor expression of neurons with 
oxygen-glucose deprivation in vitro and cerebral ischemiareperfusion in vivo," European Journal of Pharmacology, vol. 649, no. 1-3, pp. 92-99, 2010.

[32] Y. Chen, N. Lu, Y. Ling et al., "Wogonoside inhibits lipopolysaccharide-induced angiogenesis in vitro and in vivo via toll-like receptor 4 signal transduction," Toxicology, vol. 259, no. 1-2, pp. 10-17, 2009.

[33] Y. G. Wang, H. Wu, Z. Meng et al., "Effect of total flavonoids of Radix Scutellariae on TLR2/Nod2 expression in lung after infection of staphylococcus aureus in vivo and in vitro," Chinese Pharmacological Bulletin, vol. 25, no. 7, pp. 866-870, 2009.

[34] E. F. Schippers, C. van't Veer, S. van Voorden, C. A. E. Martina, S. le Cessie, and J. T. van Dissel, "TNF- $\alpha$ promoter, Nod2 and toll-like receptor-4 polymorphisms and the in vivo and ex vivo response to endotoxin," Cytokine, vol. 26, no. 1, pp. 16-24, 2004.

[35] X. F. Xu, B. L. Cai, B. Liu et al., "Baicalin induces human mucoepidermoid carcinoma Mc3 cells apoptosis in vitro and in vivo," Investigational New Drugs, vol. 29, pp. 637-645, 2010.

[36] J. F. Zhang, R. Huang, Y. J. Yang, R. Z. Huang, and Y. M. $\mathrm{Su}$, "Effect of baicalin preconditioning on neuron apoptosis in the rats with experimental autoimmune encephalomyelitis," Chinese Pediatric Emergency Medicine, vol. 16, pp. 564-567, 2009.

[37] J. Q. Yin, H. M. Chen, W. M. Luo, J. N. Shen, X. Y. Zheng, and Q. Jia, "In vitro studies of baicalein and baicalin mediated apoptosis in human osteosarcoma cell line U-2OS and U-2OS/MTX (300)," West China Journal of Pharmaceutical Sciences, vol. 26, pp. 133-135, 2011.

[38] Z. Gong, Y. X. Cheng, M. Zhang, T. T. Song, J. F. Lv, and K. J. Ning, "Effects of baicalin on anti-oxidation function in liver of liver injury mice," Journal of Anhui Science and Technology University, vol. 25, pp. 5-8, 2011.

[39] J. Tao, Q. Hu, J. Yang et al., "In vitro anti-HIV and -HSV activity and safety of sodium rutin sulfate as a microbicide candidate," Antiviral Research, vol. 75, no. 3, pp. 227-233, 2007.

[40] H. H. Lee, L. L. Yang, C. C. Wang, S. Y. Hu, S. F. Chang, and Y. H. Lee, "Differential effects of natural polyphenols on neuronal survival in primary cultured central neurons against glutamate-and glucose deprivation-induced neuronal death," Brain Research, vol. 986, no. 1-2, pp. 103-113, 2003.

[41] R. V. Macri, J. Karlovská, G. F. Doncel et al., "Comparing antiHIV, antibacterial, antifungal, micellar, and cytotoxic properties of tricarboxylato dendritic amphiphiles," Bioorganic and Medicinal Chemistry, vol. 17, no. 8, pp. 3162-3168, 2009.

[42] F. López-Neblina and L. H. Toledo-Pereyra, "Anti-ischemic effect of selectin blocker through modulation of tumor necrosis factor- $\alpha$ and interleukin-10," Journal of Surgical Research, vol. 138, no. 2, pp. 275-283, 2007.

[43] J. Hao, W. Shen, C. Tian et al., "Mitochondrial nutrients improve immune dysfunction in the type 2 diabetic GotoKakizaki rats," Journal of Cellular and Molecular Medicine, vol. 13, no. 4, pp. 701-711, 2009.

[44] C. Li, L. Zhou, G. Lin, and Z. Zuo, "Contents of major bioactive flavones in proprietary traditional Chinese medicine products and reference herb of Radix Scutellariae," Journal of Pharmaceutical and Biomedical Analysis, vol. 50, no. 3, pp. 298-306, 2009.

[45] K. L. Li and S. J. Sheu, "Determination of flavonoids and alkaloids in the scute-coptis herb couple by capillary electrophoresis," Analytica Chimica Acta, vol. 313, no. 1-2, pp. 113-120, 1995.
[46] N. Inohara and G. Nuñez, "NODS: intracellular proteins involved in inflammation and apoptosis," Nature Reviews Immunology, vol. 3, no. 5, pp. 371-382, 2003.

[47] C. Eskes, L. Juillerat-Jeanneret, G. Leuba, and P. Honegger, "Involvement of microglia-neuron interactions in the tumor necrosis factor- $\alpha$ release, microglial activation, and neurodegeneration induced by trimethyltin," Journal of Neuroscience Research, vol. 71, no. 4, pp. 583-590, 2003.

[48] E. Meylan, J. Tschopp, and M. Karin, "Intracellular pattern recognition receptors in the host response," Nature, vol. 442, no. 7098, pp. 39-44, 2006.

[49] K. B. Vartanian and M. P. Stenzel-Poore, "Toll-Like receptor tolerance as a mechanism for neuroprotection," Translational Stroke Research, vol. 1, no. 4, pp. 252-260, 2010.

[50] Y. Cao, X. Mao, C. Sun et al., "Baicalin attenuates global cerebral ischemia/reperfusion injury in gerbils via anti-oxidative and anti-apoptotic pathways," Brain Research Bulletin, vol. 85, no. 6, pp. 396-402, 2011.

[51] H. Takahashi, M. C. Chen, H. Pham et al., "Baicalein, a component of Scutellaria baicalensis, induces apoptosis by Mcl-1 down-regulation in human pancreatic cancer cells," Biochimica et Biophysica Acta, vol. 1813, no. 8, pp. 1465-1474, 2011.

[52] S. T. Huang, C. Y. Wang, R. C. Yang, C. J. Chu, H. T. Wu, and J. H. S. Pang, "Wogonin, an active compound in Scutellaria baicalensis, induces apoptosis and reduces telomerase activity in the HL-60 leukemia cells," Phytomedicine, vol. 17, no. 1, pp. 47-54, 2010. 

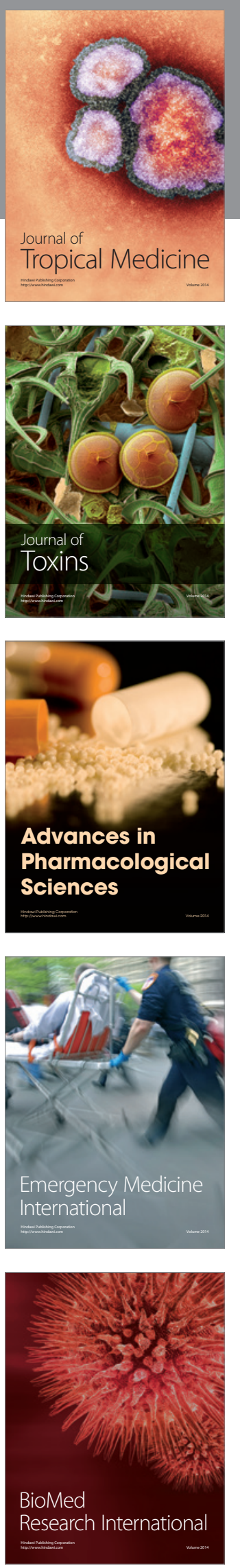
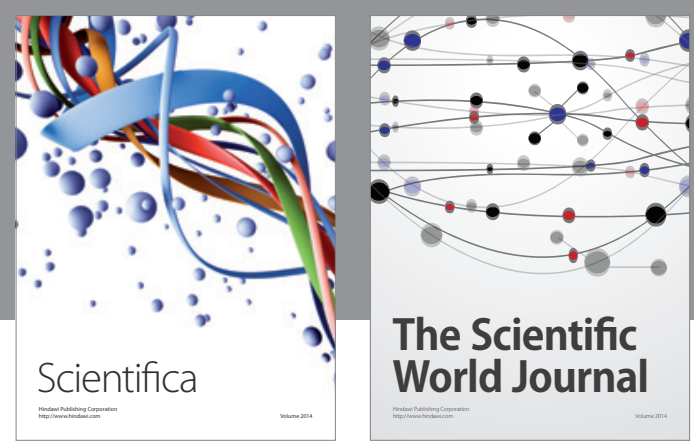

The Scientific World Journal
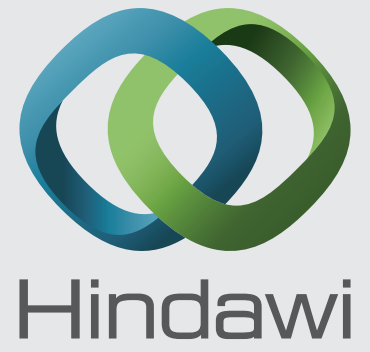

Submit your manuscripts at

http://www.hindawi.com
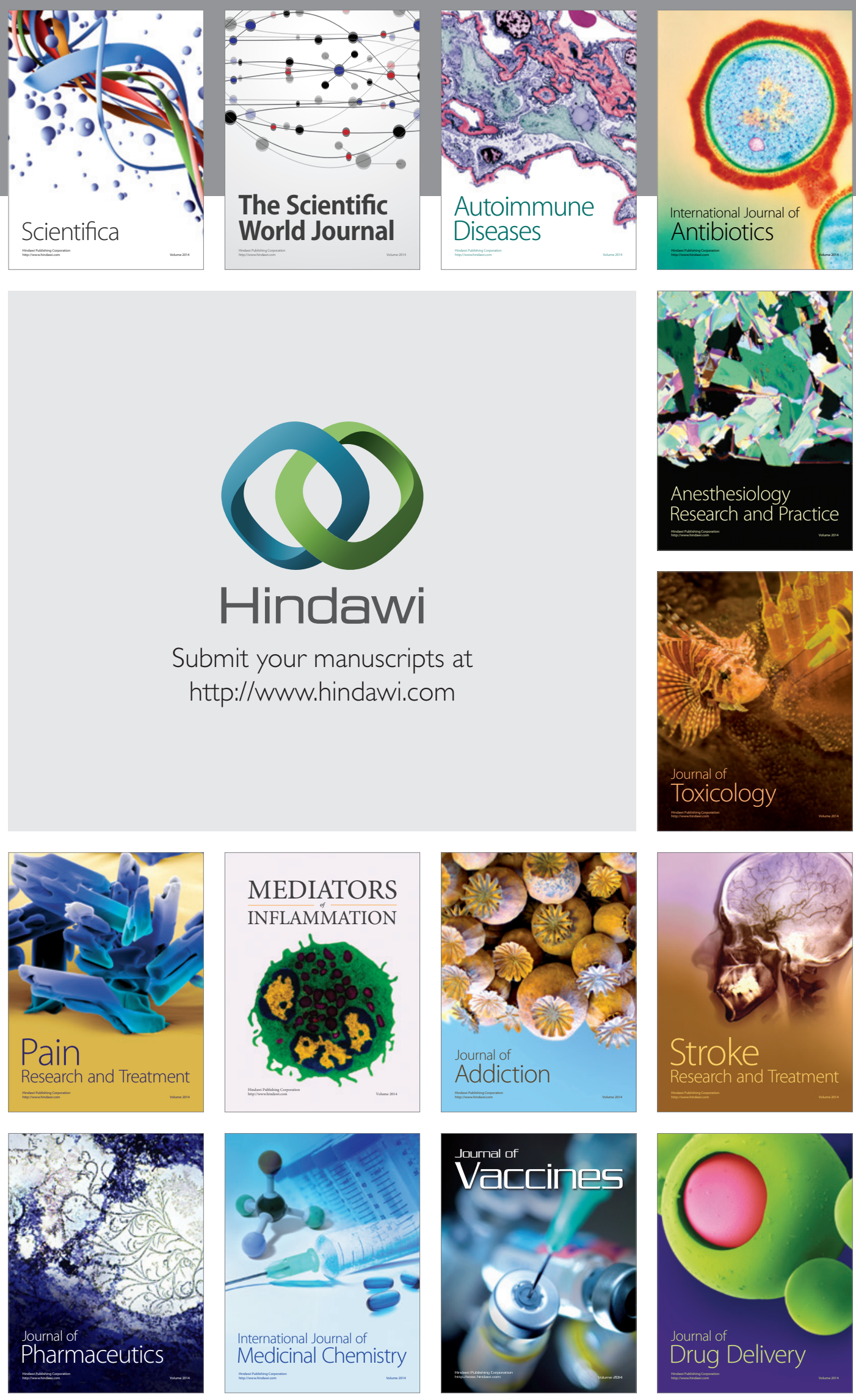